NBER WORKING PAPER SERIES

\title{
EUROPEAN EXCHANGE RATE CREDIBILITY BEFORE THE FALL
}

Andrew K. Rose

Lars E. O. Svensson

Working Paper No. 4495

\author{
NATIONAL BUREAU OF ECONOMIC RESEARCH \\ 1050 Massachusetts Avenue \\ Cambridge, MA 02138 \\ October, 1993
}

We thank Sveriges Riksbank for assistance with the data set, and Magnus Dalhquist for research assistance. For hospitality and research support during the course of this research Rose thanks: FRBSF; H.M. Treasury; IIES; and the IMF; Svensson thanks the Swedish Council for Research in the Humanities and Social Sciences. For comments, we also thank: Bill Branson; Robert Gordon; Guido Tabellini; and participants at the June 1993 LSE Financial Markets Group Conference, and the 1993 International Seminar on Macroeconomics. This paper is part of NBER's research program in International Finance and Macroeconomics. Any opinions expressed are those of the authors and not those of the National Bureau of Economic Research. 


\title{
EURCPEAN EXCHANGE RATE \\ CREDIBILITY BEFORE THE FALL
}

\begin{abstract}
Realignment expectations which measure exchange rate credibility are analyzed for European exchange rates, using daily financial data since the inception of the EMS. It is difficult to find economically meaningful relationships between realignment expectations and macroeconomic variables, although there are signs that lower inflation improves credibility. Statistically, many movements to realignment expectations are common to ERM participants. There were few indications of poor ERM credibility before late August 1992; the dimensions of the currency crisis of September 1992 appear to have taken both policy-makers and private agents largely by surprise.
\end{abstract}

Andrew K. Rose

School of Business Administration

350 Barrows Hall

University of California

Berkeley, CA 94720

and NBER
Lars E. O. Svensson

IIES

Stockholm University

S-106 91

Stockholm, Sweden

and NBER 


\section{I: Introduction and Motivation}

Since the inception of the European Monetary System (EMS) in early 1979, eleven governments have linked their exchange rates through formal participation in the Exchange Rate Mechanism (ERM); a number of other countries (such as Austria, Norway and Sweden) have participated in a more informal, unilateral manner. The objective of this paper is to characterize empirically the perceived credibility of these exchange arrangements. More precisely, the objective of this research is to understand better the causes, effects and behavior of European exchange rate realignment expectations during the EMS. Special attention is paid to the ERM in the period preceding the currency crisis of Autumn 1992.

Our research is motivated by the generally poor level of understanding of the empirical causes and characteristics of credibility. This gap in knowledge may have profound consequences; if policy makers are to be able to manipulate the level of credibility, they must first have a clear view about the determinants of realignment expectations. Whereas the literature has developed precise methods of measuring realignment expectations, it has only been able to shed a little light on the actual causes of realignment expectations (see e.g., Lindberg, Svensson and Söderlind, (1991), Koen (1991), or the complementary and independent study by Chen and Giovannini (1993); Caramazza (1993) provides somewhat more positive results).

On a different note, we would like to understand realignment expectations in the European currency crisis which began in September 1992. Were macroeconomic divergences the ultimate causes of poor credibility and the currency crisis? For instance, had the underlying problems been clearly brewing because of the loose fiscal and tight German monetary policy experienced since Unification (as some have alleged), or because of slow persistent real exchange rate divergence since the last general ERM realignment of 1987? Such explanations seem intuitively plausible, yet are worth examining since it is notoriously difficult to link macroeconomic conditions to flexible exchange rates with 
statistical criteria. Altematively, was either the imminent prospect of European Monetary Union (EMU) or its possible deferral (as a result of the Danish and French referenda on the Maastricht Treaty) an important source of the problem? In this case, we might expect news about the outcome of the referenda to be manifest in credibility measures. Or was the crisis more financial and speculative in nature (as suggested in the popular press), largely independent of underlying political and economic fundamentals, and therefore less susceptible to correction by official policy?

We find that the credibility of European exchange rate pegs varies significantly over time, mostly for reasons which cannot be well explained by standard macroeconomic variables. There are signs that higher inflation differentials (vis-a-vis Germany, the center of the EMS) reduces credibility. However, exchange rate realignment expectations generally appear to be relatively disconnected from macroeconomic phenomena, to a degrce that is disconcerting from an economist's point of view. Many movements of realignment expectations are common to ERM participants; that is, much credibility is shared by all members of the system. But this general credibility factor, like a typical floating exchange rate, moves dramatically over time, frequently reacting to economic non-events and not moving consistently in response to events which would appear to be relevant from a theoretical viewpoint. Perhaps the most dramatic illustration of the latter point was the relatively high level of ERM credibility which persisted until late August 1992, despite a variety of pieces of relevant economic and political news. That is, the currency crisis of 1992 does not appear to have been anticipated by financial markets. Both private-sector agents as well as policy-makers appear to have been taken by surprise by the events and aftermath of mid-September.

In the next part of the paper, we discuss how to measure expectations of exchange rate realignments, i.e., credibility. After a brief discussion of our data set in Section III, we present our actual measures of realignment expectations. In section $V$, we analyze the 
macroeconomic determinants of realignment expectations using non-structural econometric techniques. This is followed by a characterization of the common component of credibility. Section VII draws out certain implications of our analysis for the currency crisis; the paper ends with a brief conclusion.

\section{II: Measuring Realignment Expectations}

In this section of the paper, we briefly discuss a variety of different ways to measure realignment expectations. These methods have been used extensively; the reader is referred to Rose and Svensson (1993), Lindberg, Svensson, and Söderlind (1991), and Svensson (1993) for further analysis.

We use two measures of realignment expectations in our study: raw interest differentials; and interest differentials adjusted for expected exchange rate drift (the "driftadjustment" method). Clearly these measures are closely related; reassuringly, they also typically deliver the same message.

We let $\delta_{\mathrm{t}}$ denote the differential between the domestic currency interest rate (on Eurodeposits of a given maturity $\Delta t$ ) and the Deutschemark interest rate on a similar security. If the (natural logarithm of the nominal) spot price of a Deutschemark (DM) in domestic currency at time $t$ is denoted $s_{t}$, then uncovered interest parity can be expressed as:

$$
\delta_{\mathrm{t}}=\mathrm{E}_{\mathrm{l}}\left[\Delta \mathrm{s}_{\mathrm{l}}\right] / \Delta \mathrm{t}
$$

where: $E_{q}$ denotes the expectations operator conditional upon information available at time $\mathrm{t}$, and $\Delta \mathrm{s}_{\mathrm{t}} \equiv \mathrm{s}_{\mathrm{t}+\Delta t}-\mathrm{s}_{\mathrm{t}}$. Thus interest rate differentials reflected the total rate of expected depreciation of the domestic currency. ${ }^{1}$ 
The total rate of expected depreciation can be separated into two parts:

$$
\mathrm{E}_{\mathrm{l}}\left(\Delta \mathrm{s}_{\mathrm{l}}\right) / \Delta \mathrm{t}=\mathrm{E}_{\mathrm{l}}\left(\Delta \mathrm{x}_{\mathrm{j}}\right) / \Delta \mathrm{t}+\mathrm{E}_{\mathrm{l}}\left(\Delta \mathrm{c}_{\mathrm{l}}\right) / \Delta \mathrm{t}
$$

where $x_{t}$ denotes the deviation of the $\log$ of the spot rate from $c_{1}$, the $\log$ of the central parity, and thus $s_{1} \equiv c_{1}+x_{t}$. The object of interest to us is $E_{1}\left(\Delta c_{1}\right) / \Delta t$, the expected rate of change of the central parity (i.e., the expected rate of realignment), which we also denote by $\mathrm{g}_{t}{ }^{2}$ We think of a high value of $\mathrm{g}$ as indicating poor credibility, low (or even negative) values being manifestations of high credibility.

We measure realignment expectations in two ways. The easiest alternative is simply to use the interest rate differential, $\delta$; this strategy makes sense under the assumption $\mathrm{E}_{\mathrm{l}}\left(\Delta \mathrm{x}_{\mathrm{v}}\right) / \Delta \mathrm{t}=0$. Since no estimation need be undertaken, this measure has the advantage of simplicity. It has the disadvantage that it ignores potentially non-trivial expected changes in $x$, which may be relevant if there is substantial mean-reversion and volatility in $x$, the exchange rate within the band. Thus, our second and preferred measure of credibility relies on $g$, i.e., adjusting $\delta_{q}$ for expected exchange rate drift by subtracting an estimate of $E_{l}\left(\Delta x_{j}\right) / \Delta t$, the drift-adjustment method. The price to be paid for a more precise estimate of $g$ is the set of complications arising from the fact that the adjustment term, $E_{1}\left(\Delta x_{1}\right) / \Delta t$, is unknown and must therefore be estimated.

Rose and Svensson (1993) and Lindberg, Svensson and Söderlind (1991) review a variety of different methods of estimating $\mathrm{E}_{\mathrm{l}}(\Delta \mathrm{x}) / \Delta \mathrm{t}$; our results will typically be quite insensitive to the exact choice of estimation technique. Our default technique relies on OLS estimation of:

$$
\left(x_{t+\Delta t}-x_{v}\right) / \Delta t=\Sigma_{j} \alpha_{i}+\beta x_{t}+\gamma \delta_{t}+u_{t+\Delta t}
$$


where: $u_{t+\Delta t}$ is a forecast error realized at time $t+\Delta t$, assumed to be orthogonal to information available at time $\mathrm{t}$ (but certainly not serially independent, so that a corrected covariance matrix must be used); and the different intercepts correspond to the periods between realignments vis-a-vis the DM. This equation should be interpreted as a statistical projection, rather than as anything structural. ${ }^{3}$

\section{III: Data}

Our chief data base consists of daily observations on exchange and interest rates collected at the end of October 1992. These data were obtained from the BIS database. The data set begins with the start of the EMS on March 13,1979, and ends on October 26, 1992. The exchange rate data are mid-ecu-rates recorded at 2:30 pm Swiss time. The interest rates are annualized Euro-interest bid rates (which should be relatively free of political risk), recorded at 10:00 am Swiss time. So as to sharpen our focus on short-term realignment expectations, we use one-month and three-month maturities for our interest rates. In practice, we typically focus on the period since November 1981, since the Irish interest rate data are only available after that date. We collected data for Germany and the six long-term participants in the ERM: Belgium (which maintains an exchange peg of unity to Luxembourg); Denmark; Eire; France; Holland; and Italy. For some purposes, we also use comparable data for the more recent ERM participants (Spain, the UK, and Portugal). To compare ERM participants with unilateral pegs, we also collected data for Austria, Norway and Sweden." Throughout, Germany is treated as the base country, both because of its role as the traditional anchor of the ERM, and to emphasize the special role of German macroeconomic shocks in the events leading up to 1992.

We checked the data set in a number of ways, including visual assessment of both the levels and growth-rates of the series, as well as checking for outliers (defined as observations lying outside three sample standard deviations of the sample mean on a year- 
by-year basis) by comparing our data with independent figures in The Financial Times. On the basis of these filters, we have identified seven questionable observations; we treat these observations as missing for the purpose of our analysis."

The raw exchange rate data (DM rates scaled by 100) are portrayed in Figure 1, which also shows the notional limits for the six ERM participants. Interest differentials for the three-month maturity are portrayed in Figure 2; comparable series for the one-month maturity are similar. We define "regimes" as periods between actual ERM realignment; in Figure 2 these are delineated with vertical lines.

We also use a number of macroeconomics series in our study. These series were extracted from the IMF's International Financial Statistics compact disk. The data are monthly and are available from March 1979 through September 1992 (with a few exceptions, which are available somewhat later). The "real exchange rate" is an effective multilateral exchange rate index number $(1985=100)$, based on relative normalized unit labor costs in manufacturing (IFS mnemonic ..reu); "money" is Reserve Money (IFS line 14); "inflation" is the rate of change of the consumer price index (IFS line 64..x); "output" is an index of industrial production (IFS line $66 . . \mathrm{b}$ or $66 . \mathrm{c}$ ); the "trade balance" is exports over CIF imports (IFS line 70 over IFS line 71); and "reserves" is total reserves minus gold (IFS line 11.d). These series have also been checked and corrected where necessary. With the exception of the inflation rate, all of the macroeconomic variables have been transformed by taking deviations of natural logarithms of domestic values from (logs of) German values.

Figures 3 through 8 are time series graphs of the ERM macroeconomic variables. Money and price level growth rates are portrayed; the remaining variables are in log-levels (of differences between the domestic and German variables). In each graph, six series are presented; " $\mathrm{B}$ " denotes the Belgian data; " $\mathrm{D}$ " marks the Danish data; " $E$ ", Irish data; " $F$ " France"; "H" Holland; and "I" Italy. While the inflation rates appear to have converged 
somewhat by 1992, this convergence is not as apparent in the other macroeconomic variables.

\section{IV: Measures of Realignment Expectations}

Table I contains estimates of equation (3), estimated with daily data over the entire available sample since the beginning of the ERM (the Irish sample is shorter than that of the other currencies, since the Irish interest rate data are only available from late 1981). Observations which overlap an actual realignment are excluded, as described in Rose and Svensson (1993). The equation is estimated with OLS, but the standard errors have been corrected for heteroskedasticity and the serial correlation which necessarily results from the "overlapping observations" problem, with a Newey-West covariance estimator. Results are tabulated for the one-month market; results are similar for the three-month maturity.

The results indicate substantial mean-reversion in the $x$ process for each of the ERM currencies; the coefficients on $x$ are large in both economic and statistical terms, soundly rejecting the hypothesis that $\mathrm{x}$ has a unit-root for each currency except the Irish punt (which is a more marginal case, possibly resulting from the shorter sample). The coefficients on the interest rate differential are negative and frequently significant; a high domestic interest rate relative to the German rate, is associated with appreciation. Intercepts vary substantially across regimes.

Three diagnostics follow the coefficients tabulated in Table I: $N$, the sample size; $\dot{\sigma}$, the estimated residual standard error; and $\sigma(\Delta x / \Delta t)$, the sample standard deviation of the regressand. It should be noted that the standard error of the estimated residual is typically close to (but obviously always less than) the standard deviation of the dependent variable. That is, the equations predict the actual change in the exchange rate within the band relatively poorly. This is of no importance in itself, since our objective is to estimate the expected change in the exchange rate within the band, $\mathrm{E}_{\mathrm{l}}\left(\Delta \mathrm{x}_{1}\right) / \Delta \mathrm{t}$, not the actual change in 
Table I: Estimates of (3)

Estimates of Expected Rate of Depreciation Within Band (1-month horizon)

Coefficients:

\begin{tabular}{lcccccc}
\hline & Denmark & Belgium & France & Holland & Italy & Eire \\
$\mathrm{x}$ & -2.41 & -1.62 & -1.82 & -3.03 & -1.10 & -1.21 \\
& $(.43)$ & $(.35)$ & $(.47)$ & $(.81)$ & $(.25)$ & $(.48)$ \\
$\delta$ & -.74 & -.56 & -.15 & -1.16 & -.35 & -.54 \\
& $(.17)$ & $(.25)$ & $(.16)$ & $(.33)$ & $(.25)$ & $(.15)$ \\
Intercept 1 & 8.92 & 5.76 & 2.20 & 8.01 & -.98 & $\mathrm{n} / \mathrm{a}$ \\
& $(3.12)$ & $(1.96)$ & $(1.20)$ & $(1.46)$ & $(2.88)$ & \\
Intercept 2 & 12.93 & 2.83 & -1.66 & -1.65 & 6.63 & $\mathrm{n} / \mathrm{a}$ \\
& $(1.76)$ & $(1.42)$ & $(1.76)$ & $(.71)$ & $(2.66)$ & \\
Intercept 3 & .60 & 5.27 & 4.55 & .65 & 6.72 & 6.86 \\
& $(1.46)$ & $(1.46)$ & $(3.01)$ & $(.22)$ & $(3.37)$ & $(2.90)$ \\
Intercept 4 & .06 & 12.67 & 2.22 & $\mathrm{n} / \mathrm{a}$ & 9.64 & 7.78 \\
& $(1.85)$ & $(5.38)$ & $(2.27)$ & & $(3.99)$ & $(2.53)$ \\
Intercept 5 & 7.00 & 6.47 & -1.26 & $\mathrm{n} / \mathrm{a}$ & 7.73 & 2.78 \\
& $(3.55)$ & $(1.85)$ & $(1.25)$ & & $(4.35)$ & $(1.29)$ \\
Intercept 6 & 5.32 & 3.40 & 2.31 & $\mathrm{n} / \mathrm{a}$ & 3.50 & 7.41 \\
& $(2.43)$ & $(1.09)$ & $(2.10)$ & & $(2.92)$ & $(3.76)$ \\
Intercept 7 7) & .67 & 4.43 & 2.16 & $\mathrm{n} / \mathrm{a}$ & 4.39 & 2.99 \\
& $(1.17)$ & $(1.06)$ & $(.73)$ & & $(2.57)$ & $(1.47)$ \\
Intercept 8 & 5.07 & 1.85 & $\mathrm{n} / \mathrm{a}$ & $\mathrm{n} / \mathrm{a}$ & 1.72 & 2.07 \\
& $(1.59)$ & $(.53)$ & & & $(1.75)$ & $(.56)$ \\
Intercept 9 & 4.51 & $\mathrm{n} / \mathrm{a}$ & $\mathrm{n} / \mathrm{a}$ & $\mathrm{n} / \mathrm{a}$ & 4.16 & $\mathrm{n} / \mathrm{a}$ \\
& $(.85)$ & & & & $(1.96)$ & \\
Intercept 10 & $\mathrm{n} / \mathrm{a}$ & $\mathrm{n} / \mathrm{a}$ & $\mathrm{n} / \mathrm{a}$ & $\mathrm{n} / \mathrm{a}$ & 1.09 & $\mathrm{n} / \mathrm{a}$ \\
& & & & & $(1.23)$ & \\
Diagnostics: & & & & & & \\
\hline$N$ & 3151 & 3179 & 3207 & 3286 & 3027 & 2482 \\
$\hat{\sigma}$ & 5.75 & 4.65 & 5.74 & 3.46 & 8.47 & 4.98 \\
$\sigma(\Delta x / \Delta t)$ & 6.66 & 5.24 & 6.23 & 3.94 & 8.81 & 5.57
\end{tabular}

Significance Levels for Hypothesis Tests of Exclusion Restrictions:

$\begin{array}{lllllll}\text { Lags } & .52 & .79 & .29 & .41 & .00^{* *} & .13 \\ \text { Non-linear } & .42 & .11 & .28 & .03^{*} & .22 & .28 \\ \text { Limits } & .01^{* *} & .16 & .00^{* *} & .28 & .16 & .30 \\ \text { Joint } & .18 & .17 & .00^{* *} & .03^{*} & .01^{* *} & .23\end{array}$

OLS Estimates with Newey-West standard errors (computed with 22 off-diagonal bands) in parentheses; one month interest maturity; sample excludes periods one month before actual realignments. All variables scaled by 100 . 
the exchange rate within the band, $\Delta x_{1} / \Delta t$.

Equation (3) is also compared to a more general specification which includes: five lags of $\mathrm{x}$; quadratic and cubic powers of $\mathrm{x}$; and deviations from effective bilateral ERM upper and lower limits. ${ }^{6}$ The significance levels for four hypothesis tests are tabulated: 1) "Lags" tests the null hypothesis that the five daily lags of $x$ are jointly insignificant; 2) "Non-linear" tests for significance of the higher-order $x$ terms; 3) "Limits" tests whether effective ERM limits matter; and 4) "Joint" tests 1) through 3) jointly. Rejections of the null hypothesis at the .05 (.01) level are marked by an asterisk(s). The joint test is rejected for France, Holland and Italy, for three different reasons. We stick to (3) for uniformity.

Figure 9 contains time series graphs of $95 \%$ confidence intervals for the resulting (three-month) estimates of $\mathrm{g}$ from March 1979 through October 1992 (one-month results are similar). Again, actual realignments are marked with a vertical line. The units of $g$ measure expected realignment rates, and should be interpreted as the product of the expected realignment size times the expected realignment frequency. Thus a value of $10 \%$ $\mathrm{p} / \mathrm{a}$ indicates that a realignment of $5 \%$ (a typical ERM realignment size) has an expected frequency of $2 \mathrm{p} / \mathrm{a}(=10 \%$ annually/5\%), or a $.5(=2 / 4)$ probability of realignment in the subsequent quarter.

Figure 9 shows that ERM exchange arrangements clearly lacked perfect credibility in the sense that realignment expectations were typically non-negligible throughout the sample. The positive values indicate expectations of devaluation against the DM, although there are occasionally signs of expected DM devaluation. This result is quite consistent with the existing literature; see e.g. Svensson (1993). A downward drift in the series (indicating increasing credibility) is also noticeable from the 1987 realignment until the late summer of 1992.' Many movements appear to be common across currencies, both trends and individual episodes. There is also an unsurprising similarity between the measures of realignment expectations in Figure 9, and the raw interest rate data of Figure 2. This 
similarity also extends across maturity; for all countries, the levels and first-differences of the four measures ( $\delta$ and $g$ for two maturities) are highly positively correlated.

\section{V: Determinants of Realignment Expectations}

In this section, we investigate the determinants of realignment expectations using reduced-form techniques. We are interested in seeing whether there is a tight link between macroeconomic variables and our measures of realignment expectations. The set of macroeconomic variables which we investigate is relatively broad, and includes most plausible candidates that are either implied by theoretical work, or that have been mentioned in the popular press.

Traditional monetary models of exchange rate determination with flexible prices imply that the "fundamentals" driving exchange rates are linear combinations of money and output; thus money and output are obvious candidates for macroeconomic variables worthy of inclusion. Comparable monetary models with sticky prices are augmented by additional terms involving inflation, which is therefore also included (Flood and Rose (1992) provide references and details). As Eichengreen and Wyplosz (1993) show, various models of balance of payments crises assign key roles to actual or expected levels of international reserves, trade balances, and the real exchange rate. The latter variable is particularly important insofar as it measures the cumulative impact of different trends in competitiveness. We therefore treat all of these as potentially important determinants of credibility.

We are also interested in investigating the link between implicit bandwidth, monetary independence, and realignment expectations. One of us has argued that exchange rate bands give central banks some degree of monetary independence even with free capital mobility (Svensson (1992)). This monetary independence can be used, e.g., to smooth the domestic interest rate response to shocks to foreign interest rates or realignment 
expectations, by allowing counter-acting exchange rate fluctuations within the band. However, a few countries (Austria from 1982, Holland from 1983, Belgium from 1990, and Sweden during part of 1992) have conspicuously abstained from exploiting any monetary independence within the band, and instead pegged their exchange rates very closely to the central parity. Some time after this occurred, realignment expectations all but vanished, with the exception of Sweden. Hence, we are lead to the hypothesis that not exploiting potential monetary independence improves credibility. Towards that end, we therefore investigate the linkages between our measures of realignment expectations and the amount of monetary independence exploited within the band. The latter is measured by the standard deviation of expected future exchange rate drift within the band. The notable exception to our list of potential credibility determinants stems from our inability to find a reliable measure of fiscal policy at the monthly frequency.

We begin our investigation by temporally aggregating our daily observations of realignment expectations to the monthly frequency, in order to be able to compare our measures with macroeconomic data. We then stack the monthly observations for our six ERM countries into a panel. (We focus on the ERM countries both because of EMSspecific institutional features like the short-term financing facilities, and because of the general agreement that Germany acts as the center country for the system, implying that our macroeconomic variables can be expressed as deviations from German values. Countries with their own currency baskets like Norway and Sweden should be compared with an appropriately country-weighted average of macroeconomic variables). We choose not to go to the quarterly frequency, even though that would enable us to use national accounts and balance of payments data, since one of the most striking features of our credibility measures is their volatility, a feature which might be lost with further temporal aggregation. 
We begin our exploration by running contemporaneous regressions of our realignment expectations measures on the six macroeconomic variables and our measure of exchange rate volatility in levels. The estimated coefficients clearly cannot be interpreted as being structural in any sense, since credibility may feed back to macroeconomic performance or exchange rate volatility. ${ }^{8}$ The panel regressions are augmented by country and year dummies. Thus we estimate the following equation:

$$
\begin{aligned}
g_{i n}= & \Sigma_{i} \alpha_{i}+\Sigma_{r} \alpha_{i} \text { Year }_{n}+\beta^{\circ}\left[\sigma_{i n}(E(\Delta x) / \Delta t)\right] \\
& +\beta^{m} m_{i \hbar}+\beta^{r} r_{i k}+\beta^{q} q_{i n}+\beta^{p} p_{i n}+\beta^{y} y_{i n}+\beta^{b} b_{i n}+v_{n}
\end{aligned}
$$

where: $g_{i}$ is the mean of $g$ (at a given maturity) for country $\mathrm{i}$ during month $\mathrm{t} ;\left\{\alpha_{i}\right\}$ is a set of country-specific dummies which control for e.g., time-invariant institutional features of our countries; $\left\{\right.$ Year $\left._{n}\right\}$ is a set of year-specific dummies which can account for e.g. oil shocks which affect countries similarly; $\sigma_{i n}(E(\Delta x) / \Delta t)$ denotes the standard deviation during month $t$ of the expected drift in exchange rate $i$ within the band, derived from estimates of (3), and is our measure of monetary independence; $m$ is the (difference between the natural logarithms of domestic and German values of the) money supply; $r$ denotes reserves; $q$ is the real exchange rate; $p$ is the inflation rate; $y$ is output; $b$ is the trade balance; and $v_{i t}$ is a disturbance, assumed to be well-behaved, i.e., orthogonal to the regressors. This equation is estimated with OLS; standard errors are computed with autocorrelation- and heteroskedasticity-consistent covariance estimators.

The results of estimating (4) with our ERM panel are presented in Table II. The individual coefficients of the macroeconomic variables are tabulated, as are the standard errors (which are estimated with the Newey-West correction). The estimates are not especially encouraging in the sense that there do not appear to be tight links between realignment expectations and their posited determinants. Inflation has the most precisely 
Table II: Estimates of (4)

Contemporaneous Effects of Macro-Variables on Realignment Expectations

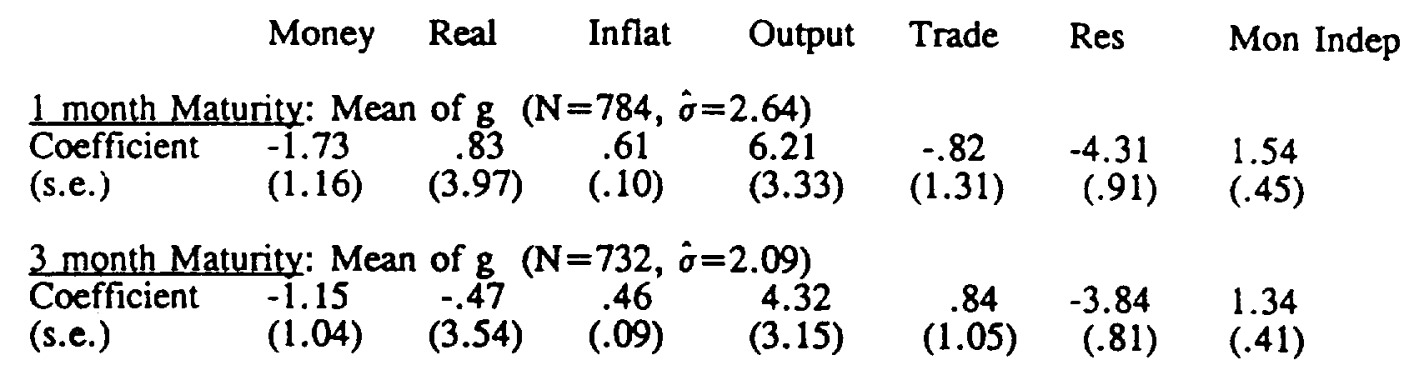

OLS Estimation of Panel of monthly data for six ERM currencies; autocorrelation- and heteroskedasticity-consistent standard errors (computed with twelve lags) in parentheses. Country and year dummies included. Variables scaled by 100 .

estimated impact on credibility; an increase in the domestic inflation rate relative to the German rate is associated with a significant increase in realignment expectations (i.e., a decrease in credibility), holding all else constant. Similarly, decreases in international reserves are also correlated with increased realignment expectations. Increases in exchange rate variability and therefore the degree of exploited monetary independence are also associated with significant increases in realignment expectations. However, there do not appear to be clear links between realignment expectations and money, output, real exchange rates, or the trade balance. Similar results are obtained if interest rate differentials are used as regressands, or if the standard deviation of either the exchange rate within the band, or its first-difference is used in place of the standard deviation of expected future exchange rate drift as a measure of exploited monetary independence.

The results of Table II are suspect for a number of reasons, chiefly associated with simultaneity bias and non-stationarity of the regressors. In the absence of a structural theory of realignment expectations, we continue our exploration by estimating a VAR which incorporates the variables of interest to us; we focus on the realignment expectations equation of the VAR. We do not attempt to restrict our VAR so as to be able to interpret 
the coefficients in a structural way (or to improve efficiency). While positive results would not indicate the structural interpretation of our findings, it is more difficult to explain away negative results. Moreover, our exercise is close in spirit to the exercises that participants in financial markets may go through if they attempt to understand exchange rate credibility by projecting realignment expectations on an information set consisting of lagged values of macroeconomic variables. (This rational expectations interpretation is pursued further by Chen and Giovannini (1993).)

The VAR links exchange rate realignment expectations to our six macroeconomic variables as well as exploited monetary independence; the VAR is also conditioned on a number of other factors. The equation of greatest interest to us is:

$$
\begin{aligned}
& \mathrm{g}_{\mathrm{it}}=\Sigma_{\mathrm{i}} \alpha_{\mathrm{i}}+\Sigma_{\mathrm{r}} \alpha_{\mathrm{r}} \mathrm{Year}_{n}+\Sigma_{\mathrm{j}} \phi_{j} \mathrm{~g}_{\mathrm{i}-\mathrm{j}}+\Sigma_{j} \beta_{j} \sigma_{\mathrm{hij}}(\mathrm{E}(\Delta \mathrm{x}) / \Delta \mathrm{t}) \\
& +\Sigma_{j} \beta_{j} r_{n-j}+\Sigma_{j} \beta_{j}^{m} m_{i-j}+\Sigma_{j} \beta_{j}^{q} q_{i-j}+\Sigma_{j} \beta_{j}^{p} p_{i-j}+\Sigma_{j} \beta_{j}^{\gamma} y_{i-j}+\Sigma_{j} \beta_{j}^{b} b_{i-j}+v_{i n}
\end{aligned}
$$

We use $\mathrm{j}=1, \ldots, 6$ monthly lags as our default, but check our estimates by also reporting the case with only three lags. We are most interested in the null hypotheses $\Sigma_{j} \beta_{j}^{x}=0$ for $z=r, m, q, p, y, b, \sigma$. That is, we seek to discover whether (permanent) changes in the macroeconomic variables are associated with (permanent) changes in the level of realignment expectations, i.e., whether there are potentially important macroeconomic determinants of realignment expectations. ${ }^{9}$

Table III presents some results derived from estimation of (5) using both the one- and three-month measures of $\mathrm{g}$. The statistics tabulated are the significance levels for a variety of hypothesis tests conceming the effects of individual macroeconomic variables. A low figure indicates that the null hypothesis of no significant cumulative effect on realignment expectations of e.g., (six lags of the logarithm of domestic) money (relative to German money) can be rejected with great confidence. 
Table III: Estimates of (5)

Tests of Effects of Macroeconomic Variables on Realignment Expectations Money Real Inflat Output Trade Res Mon Indep

Effects on Mean of $\mathrm{g}$ : (Six Lags)

1 month Maturity: $(\hat{N}=749, \hat{\sigma}=1.67)$

3 month Maturity: $(\mathrm{N}=569, \hat{\sigma}=.92)$

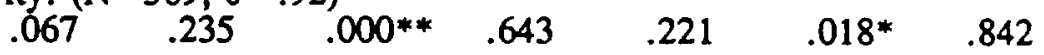

Three Lags:

1 month Maturity: $(\mathrm{N}=769, \hat{\sigma}=1.82)$

3 month Maturity: $(\mathrm{N}=646, \hat{\sigma}=1.09)$

$$
\begin{array}{lllll}
.000 * * & .896 & .940 & .136 & .700
\end{array}
$$

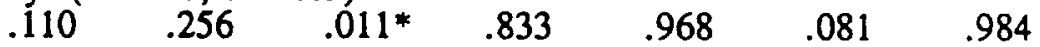

$\delta$ as regressand: (Six Lags)

1 month Maturity: $(N=749, \hat{\sigma}=1.48)$

$$
.148 \quad .384 \quad .100
$$

3 month Maturity: $(\mathrm{N}=586, \hat{\sigma}=.63)$

$.191 \quad .718 \quad .028 * \quad .055 \quad .034^{*} \quad .018 * \quad .034^{*}$

Significance levels for test of null hypothesis of no cumulative effect of variable on the mean of $\mathrm{g}$ (or $\delta$ ) in (4). OLS estimation of panel of monthly data for six ERM currencies; heteroskedasticity-consistent standard errors. Country and year dummies, and lags of the dependent variable are also included.

The relatively close link between inflation divergence and realignment expectations found in the contemporaneous regressions carries over to a dynamic model. Moreover, the coefficients consistently sum to a positive number, indicating that higher inflation is associated with higher realignment expectations and therefore reduced credibility. However, the other results of Table III are more negative. There do not appear to be statistically significant links between realignment expectations and up to six lags of the other hypothesized variables, including reserves and exploited monetary independence (the variables which were significantly related to realignment expectations contemporaneously). While individual coefficients on, e.g. particular lags of money, are statistically significant, they are canceled out by coefficients on other lags so that there are typically no significant 
cumulative effects. Apparently significant findings of linkages between macroeconomic variables and realignment expectations are also not robust in the sense that they vary with the number of lags chosen in the VAR, the maturity used to estimate credibility, and the choice of $g$ rather than $\delta$ as a measure of credibility..$^{10}$

The sensitivity of the results in Table III has been explored extensively; the finding of no significant and consistent relationship between the set of macroeconomic variables and realignment expectations characterizes a number of different perturbations of the basic methodology. For instance, if (5) is estimated either country-by-country (that is, only using the time-series variation in the data), or year-by-year (using only the pure crosssectional variation), a variety of different links between the mean of $g$ and the macroeconomic variables can be found; however, the coefficient sums vary dramatically in sign and significance from country to country and year to year." To take one example, the ties between inflation and realignment expectations are significant at the five percent level for four of the six countries when the three-month maturity is used for credibility, and the VARs are estimated with six lags. However, only one of the six countries has a significant relationship using the one-month measure of credibility, and none of the estimates are significant when the VARs are estimated with three lags (using either maturity to measure credibility). Further, either first-differencing the data, or using alternative measures of exchange rate volatility does not change the basic conclusion of no apparent relationship between macroeconomic variables and credibility. ${ }^{12,13}$

Finally, it is also of interest to investigate the effects of realignment expectations on the macroeconomic variables in the VAR. Table IV is an analogue to Table III in that it reports significance levels for a series of hypothesis tests which assume under the null that there is no cumulative effect of (six lags of) the mean of $g$ on the other variables of the VAR. There are few convincing indications that realignment expectations have an important effect on either the six macroeconomic variables or on the volatility of exchange 
Ilypothesis Tests of Effects of Realignment Expectations on Macro-Variables Money Real Inflat Output Trade Res Mon Indep Effects of Mean of $\mathrm{g}$ : (Six Lags) 1 month Maturity: .15 3 month Maturity: .07 .20 .40 .27 .06 .09 .26 $.12 \quad .96$ .82 .91 $.01^{* *} \quad .31$

Significance levels for test of null hypothesis of no cumulative effect of the mean of $g$ on variable in VAR analogue to (5). OLS estimation of panel of monthly data for six ERM currencies; heteroskedasticity-consistent standard errors. Country and year dummies, and lags of the dependent variable are also included.

rate drift. Results vary with the maturity of the credibility measure; they also vary with the lag-length used for VAR estimation. There are some indications that a sustained rise in $\mathrm{g}$ lowers the level of reserves. ${ }^{14}$

To sum up, with the potential exception of a link from inflation differentials, there are few clearly significant channels of macroeconomic influence on realignment expectations. We are not very surprised at this result, given the well-known difficulties of linking exchange rates to macroeconomic phenomena (e.g., Flood and Rose (1992)). Still, it makes us uncomfortable to realize that countries which have achieved closer macroeconomic convergence with Germany do not appear to have been consistently rewarded by financial markets with higher credibility, and thus a lower interest rate differential (given the level of the exchange rate). Stated altematively, the data do not show that high-credibility ERM countries like Holland have acquired their reputations as a result of significantly different macroeconomic behavior compared with countries like Italy. 


\section{VI: Characterizing the Shared Nature of Credibility}

The results of section $V$ indicate that it is difficult to find strong statistical evidence that there are important macroeconomic determinants of realignment expectations. Given the volatile nature of realignment expectations and the relatively smooth behavior of macroeconomic variables, this apparent non-relationship seems plausible. It is also consistent with the general difficulties associated with modeling exchange rates in both fixed and floating rate regimes; see e.g., Flood and Rose (1992) or Meese (1990).

However, another reason for the negative results of section $V$ seems worth investigating. The ERM is a multilateral peg to a central anchor, so that much credibility may be common, and shared by all system participants. Linking the realignment expectations of a single currency simply to its own macroeconomic situation may be misleading if much credibility is joint (or, put alternatively, if the shocks to realignment expectations are mostly common across countries). Further, a great deal of anecdotal evidence is consistent with the hypothesis of common realignment expectations. Indeed, "contamination" and "bandwagon" effects are part of the folklore surrounding the currency crisis of September 1992, as discussed by the Group of Ten (1993).

In this section of the paper, we characterize the nature of shared credibility. Simple descriptive statistics, as well as more rigorous factor-analytic technique show that much ERM exchange rate credibility is in fact joint. While this evidence is not an explanation of credibility, we believe that it is an important piece of the puzzle; any plausible explanation of realignment expectations should be able to rationalize our finding of an important role for shared credibility.

Simple contemporaneous correlations between one-month ERM interest differentials are presented in the lower half of Table V. The correlations are all positive and highly significant, the lowest being over .6 (with a standard error of less than .03 ); results for the three-month maturity are similar, as are results for first-differenced data. Analogues for 
Table $\mathrm{V}$

\section{Contemporaneous Correlations of Realignment Expectations across Countries}

$\begin{array}{lllllll} & \text { Denmark } & \text { Belgium } & \text { France } & \text { Holland } & \text { Italy } & \text { Eire } \\ \text { Denmark } & - & .51 & .51 & .36 & .53 & .57 \\ \text { Belgium } & .82 & - & .61 & .46 & .32 & .52 \\ \text { France } & .76 & .89 & - & .18 & .67 & .34 \\ \text { Holland } & .81 & .82 & .71 & - & .25 & .62 \\ \text { Italy } & .60 & .76 & .82 & .62 & - & .39 \\ \text { Eire } & .80 & .86 & .81 & .81 & .66 & -\end{array}$

Elements above the diagonal are contemporaneous correlations between $\mathrm{g}$ for the three-month maturity (estimated with 1588 observations); elements below are correlations between $\delta$ for the one-month maturity (1668 observations).

the three-month measures of $g$ are tabulated above the diagonal. Again, the correlations are highly significant and consistently positive, and conclusions do not change if the other maturity is used, or if the data are first-differenced. ${ }^{\text {is }}$

Factor-analytic techniques can be used to refine this analysis further, while also providing a natural way to estimate the common or shared component of ERM realignment expectations more rigorously. We estimate our factor models using the standard technique of principal factors (other estimation procedures such as iterated principal factors, or principal components, lead to similar factors). The "single-factor" model which is of interest to us is:

$$
g_{i i}=f_{t} b_{i}+e_{i n}
$$

where: $f_{1}$ is observation $t$ for the common realignment expectations factor $f$ (itself a "scored" linear combination of the country-specific credibility measures); $b_{i}$ are the "factor loadings" which link the common factor to country-specific realignment expectations; and $e_{i t}$ is a country-specific shock to realignment expectations (whose [scaled] variance is referred to as a "uniqueness"). (Parenthetically, this procedure does not attempt to clarify 
the reasons why much ERM credibility may be joint; for instance, the underlying shocks may be common, or the induced policy responses may be responsible for the phenomenon).

Table VI: Estimates of (6)

Principal-Factor Analysis Estimates

\begin{tabular}{lllllll} 
& $\begin{array}{c}\text { Denmark } \\
\text { Factor Loadings: }\end{array}$ & Belg-Lux. & France & Holland & Italy & Eire \\
\hline $\mathrm{g}_{1}$ & .69 & .63 & .82 & .04 & .68 & .57 \\
$\mathrm{~g}_{3}$ & .72 & .73 & .84 & .10 & .74 & .62 \\
$\delta_{1}$ & .77 & .90 & .81 & .00 & .89 & .86 \\
$\delta_{3}$ & .85 & .94 & .92 & .07 & .93 & .89
\end{tabular}

Uniqueness:

$\mathrm{g}_{1} \quad .44$

$\mathrm{g}_{3} \quad .46$

$\delta_{1} \quad .39$

$\delta_{3} \quad .26$

\section{.50}

.35

.18

.11

Scoring Coefficients:

\begin{tabular}{lll}
\hline $\mathrm{g}_{1}$ & .21 & .18 \\
$\mathrm{~g}_{3}$ & .16 & .21 \\
$\delta_{1}$ & .12 & .29 \\
$\delta_{3}$ & .11 & .26
\end{tabular}

Number of Observations:

First Two Eigenvalues:

$\lambda_{1}$
18

.29

.26
.26

.18

.27

.09

\section{.72}

.59

.76

.68

\section{.41}

.42

.16

.24

$g_{1}$

2590

2.33

.46
.05

.06

.00

.02

$\mathrm{g}_{3}$

2269

2.71

.79
.45

.35

.17

.09

.56

.45

.19

.14

Table VI contains statistics relevant to estimation of (6). Estimation of equation (6) works well in the sense that many movements in credibility for the ERM countries can be explained with a single factor; for example, a typical "uniqueness" (roughly the complement of a traditional $\mathrm{R}^{2}$ ) is around .4 (except for Holland, which has higher uniqueness, consistent with Holland's uncommonly credible ERM peg). There are some indications of a second factor, but this factor does not appear to have a clear interpretation and explains a much smaller proportion of the variance. The eigenvalues (of the 
correlation matrices) certainly fall off dramatically in size, typically from over 2.5 to around .5. This is consistent with the hypothesis that much ERM credibility is joint, especially given that the factor loadings are uniformly positive and high (e.g., typically around .7, except again for the case of Holland which has a consistently lower factor loading). Also consistent with the latter hypothesis is a consistent finding of much higher uniqueness for the three non-ERM countries; for this reason, the latter are not used in the analysis which follows.

Figure 10 is a time-series plot of the point estimate of one version of the extracted factor, computed with the one-month measure of $\mathrm{g} .{ }^{16}$ (The measure has been normalized to have a zero mean and unconditional sample standard deviation of unity.) Actual ERM realignments are marked by vertical lines; the ticks on the $x$-axis delineate individual calendar years. Comparable factors extracted for either the three-month measure of $\mathrm{g}$, or from either maturity of raw interest differentials are quite similar, and are highly correlated (in levels and first-differences) with this one-month factor. ${ }^{17}$

There are a number of striking features of Figure 10. The realignment expectations factor seems to move in an extremely volatile, unpredictable fashion; in fact the null hypothesis of a unit-root cannot be rejected at standard levels of significance. The last third of the sample (sometimes known as the "New EMS") is marked by substantially lower volatility, as well as a perceptible downward trend indicating growing credibility. By 1990 , general ERM realignment expectations were below historical averages, though not to an unprecedented degree. (Parenthetically, splitting the sample into periods before and after 1987 leads to virtually identical results.) This period of tranquility ended sharply late in the summer of 1992, and is the subject of the next section of the paper.

While the shared component of realignment expectations frequently moves dramatically around the time of realignments, the movements are not uniformly positive or negative. There are also many "false signals" of poor credibility which are not followed 
swiftly by realignments. The movement of realignment expectations around actual ERM realignments is analyzed more closely in Figure 11. The latter is an "event-study" set of multiple time-series graph depicting mean realignment expectations for the six long-term ERM participants during the business month immediately preceding and following the thirteen actual ERM realignments in our sample. The key point of figure 11 is that ERM realignment expectations appear not to have been unusually high immediately before (or after) the events of September 1992. This is particularly striking, given the higher level of capital mobility present in the EC during the 1992 crisis compared with previous ERM realignments, as well as the extra complications associated with EMU.

\section{VII: A Partial Characterization of the Currency Crisis}

In this section, we describe the behavior of ERM credibility during 1991 and 1992, focusing on the period preceding the currency crisis which erupted in September 1992. In particular, we search for indications that the currency crisis was associated with macroeconomic phenomena (which typically have long gestation periods, e.g., real exchange rate divergence, or the impact of German Unification), or with developments concerning EMU.

Figure 12 consists of nine small multiple time-series graphs for 1991 and 1992 . The top six graphs depict the time-series behavior of ( $95 \%$ confidence intervals for) realignment expectations for the long-term ERM participants. Individual months in 1992 are marked with ticks on the $x$-axis; vertical lines mark the Danish referendum of June 1992, and "Black Wednesday", September 161992 . Black Wednesday, four days before the French Referendum on the Maastricht Treaty, is generally considered to be both the beginning and the peak of the currency crisis. The lower three graphs respectively depict the average level of one-month interest rates and the extracted factors for both the one- and three-month measures of $\mathrm{g}$. 
The currency crisis was not preceded by a gradual deterioration in ERM credibility. Indeed, realignment expectations were essentially constant through the period after German unification. There were few indications of decaying ERM credibility after 1990, despite the increasingly dire economic news from both Germany (e.g., concerning the fiscal cost of unification and the tight monetary policy which followed) and the other ERM participants (including e.g., the British recession, the cumulative deterioration in Italian public finances, and competitiveness problems in both Italy and the U.K.). The non-response of ERM realignment expectations to these important economic factors seems surprising. However, it is consistent with the negative results of Section $V$, which found few consistent responses of credibility to macroeconomic factors. The absence of strong linkages between macroeconomic factors and credibility is also consistent with the fact that several targets of the speculative attacks of later September 1992 had apparently strong macroeconomic fundamentals (France is the most frequently cited example).

Realignment expectations also did not respond dramatically to political news about the prospects of EMU. For instance, interest differentials and $g$ fell after the Maastricht summit of December 1991 and did not move dramatically in response to the Danish and Irish referenda in June 1992..$^{18}$ (The small responses are unsurprising as the outcomes of both polls were close to expectations. ${ }^{19}$ ) The potential exception is the case of Italy, but even the Italian data were comparable to what had been previously experienced during the "New EMS". ${ }^{20}$ For these reasons, it seems hard to believe that doubts about EMU were very important in causing the problems in the EMS. If doubts about Maastricht ratification generated turbulence in the EMS, these doubts might be expected to have been manifest in realignment expectations which rose with the polls preceding the Danish and French referenda for a number of ERM currencies; but there is little evidence of this in the data.

Nevertheless, the polls probably had some effect on realignment expectations. By late August, there were growing (but still weak) indications from the financial markets that 
a general revaluation of the DM against other European currencies was called for; this realignment certainly seems to be consistent with the underlying macroeconomic fundamentals from a theoretical viewpoint. Indications of rising realignment expectations can be measured using the data graphed in Figures 10 and 12. After months of values of approximately -1.25 , around August 25 (the date of the first polls showing a slight majority against French ratification of the treaty) the one-month common factor rose, indicating worsening credibility. ${ }^{21}$ However, the movement was only a modest increase to around .8; movements of the three-month factor were similar. The common realignment expectations factor remained at around that level through the Italian devaluation of September 14 , before finally rising dramatically (to positive numbers) on "Black Wednesday", September 16, when the lira and the pound sterling dropped out of the ERM altogether. Closer evidence on this issue is presented in Figure 13, which is a set of timeseries graphs of the 1992 measures of interest differentials for the one month market for all nine partners of Germany in the ERM. It is striking that interest differentials remained low throughout the ERM until shortly before the Currency Crisis. Eichengreen and Wyplosz (1993) show similar results. It is also important to realize that neither the increase in realignment expectations in late August 1992 nor their level thereafter were without historical precedent. Figure 10 clearly indicates that the EMS had previously weathered comparable credibility "crises". Thus the data appear to indicate that financial markets (as well as policy-makers) were surprised by the events of mid-September. Financial market participants may not have been very forward-looking, although this seems hard to believe at the time of events like the various referenda on the Maastricht Treaty. Alternatively, the currency crisis may have been caused by phenomena without long detectable gestation lags.

We attribute some of the chaotic conditions on European exchange markets of midSeptember to the tactical decision not to revalue the DM against most or all European currencies, but instead to devalue the lira in a piecemeal fashion, when similar pressure 
was being experienced by other currencies (especially sterling). The fear amongst policymakers that an EMS realignment would substantially induce realignment expectations seems to have been excessively high. This is especially true since Figure 11 shows that the level of realignment expectations has typically fallen after realignments, especially realignments affecting a number of different currencies (see also Chen and Giovannini (1993)).

Nevertheless, it is striking that indications of a pending crisis did not emerge until late August 1992. Even then, our measures indicate that the movements and levels of realignment expectations were similar to those experienced in the period since 1987 . There was remarkably little discussion in the popular press of an incipient European currency crisis before the very late summer of 1992. The September 5 issue of The Economist did not cover recent currency developments; ${ }^{22}$ neither did Euromoney in its August issue. While the minutes of the American Federal Open Market Committee indicate that the FOMC discussed the impact of the European currency crisis in its meeting of October 6 , the EMS is not even mentioned in the minutes of the August 18 meeting, despite concerns about the dollar. Indeed, most of the popular financial press in the late summer of 1992 focussed on the weakness of the dollar, not the weakness of the EMS.

It is easy to claim ex post that traditional macroeconomic analyses of exchange rate developments indicated (even before German Unification) that a DM revaluation was warranted. On the other hand, the old parities had stood up well, weathering a variety of events since 1987 which might have been expected to result in realignments including: the removal of all capital controls; German Unification; the Gulf Crisis; entry of three new currencies in the ERM; dramatic British and Italian elections; and the onset of the recession of the early 1990s. The new EMS had weathered these situations well with constant or enhanced credibility and did not appear to be very well described by traditional models. Given this set of circumstances, it is perhaps understandable that neither European monetary authorities nor financial markets anticipated the crisis. 
VIII: Conclusion

Our examination of ERM realignment expectations has shown that the latter are only weakly related to standard macroeconomic phenomena. Of the variables that we examine, only inflation differentials vis-a-vis Germany affect ERM realignment expectations in a systematic way. Further, abstaining from the exploitation of monetary independence within ERM bands also seems not to reduce realignment expectations. On the other hand, the common nature of ERM credibility is a stylized fact in search of a theory. Perhaps our most striking result is that financial markets do not seem to have anticipated the currency crisis of September 1992.

The dramatic events of the 1992 currency crisis certainly seem to be consistent with standard economic theories. For instance, the combination of loose fiscal and tight monetary policy in Germany would be expected in a variety of models to lead to a real DM appreciation in the early 1990s, much as the same combination of American policy implied a real dollar appreciation a decade earlier. However, a note of caution is warranted even about this result, since standard exchange rate models generally have a dismal empirical performance (Meese (1990)).

Nevertheless, a real DM appreciation does not necessarily imply a nominal depreciation; it can also be achieved through lower inflation in the rest of the ERM compared with Germany. Ex ante, the latter appeared to be a more difficult route to follow than the former; ex post, both alternatives were used. On balance then, a nominal DM appreciation appears to have been a likely result of German Unification, though not a complete necessity. Also, the underlying tension between national monetary policies, fixed exchange rates, and capital mobility had long been well noted, and lead to doubts about the sustainability of the ERM, all aided by uncertainty about EMU. It remains a mystery that the deepest financial markets in the world yielded so remarkably few indications of an imminent crisis. As noted above, realignment expectations rose significantly after the 
Danish referendum only for the Italian lira. That is, there were few indications of a pending widespread currency crisis that would affect currencies with strong economic fundamentals like France and Denmark.

What did cause the ERM's fall from grace? There are two standard explanations: either doubts about EMU, or the unwillingness of policy-makers to react to the shock of German Unification with a general realignment of the ERM. These explanations may seem convincing ex post; nevertheless, neither financial markets nor policy makers seem to have been convinced ex ante. 


\section{References}

Caramazza, Francesco (1993) "French-German Interest Rate Differentials and TimeVarying Realignment Risk" IMF WP 93/1.

Chen, Zhaohui and Alberto Giovannini (1992) "Estimated Expected Exchange Rates Under Target Zones" NBER WP \#3995.

Chen, Zhaohui and Alberto Giovannini (1993) "The Determinants of Realignment Expectations Under the EMS" NBER WP $\$ 4291$.

Commission of the European Communities (1993) XXVIth General Report on the Activities of the European Communities 1992 (Brussels: EC).

Eichengreen, Barry and Charles Wyplosz (1993) "The Unstable EMS" forthcoming Brookings Papers on Economic Activity.

Flood, Robert A. and Andrew K. Rose (1992) "Fixing Exchange Rates: A Virtual Quest for Fundamentals" IIES Seminar Paper \#529.

Froot, Kenneth A. and Kenneth Rogoff (1991) "The EMS, the EMU, and the Transition to a Common Currency" NBER Macroeconomics Annual 6, 269-317.

Froot, Kenneth A. and Richard H. Thaler (1990) "Anomalies: Foreign Exchange" Journal of Economic Perspectives 4-3, 179-192.

Group of Ten (1993) International Capital Movements and Foreign Exchange Markets.

Koen, Vincent R. (1991) "Testing the Credibility of the Belgian Hard Currency Policy" IMF WP $91 / 79$.

Lindberg, Hans, Lars E.O. Svensson, and Paul Söderlind (1991) "Devaluation Expectations: The Swedish Krona 1981-1991", IIES Seminar Paper $\$ 495$.

Meese, Richard A. (1990) "Currency Fluctuations in the Post-Bretton Woods Era" Journal of Economic Perspectives 4-1, 117-134.

Rose, Andrew K., and Lars E.O. Svensson (1993) "Expected and Predicted Realignments", mimeo.

Svensson, Lars E.O. (1992) "Why Exchange Rate Bands? Monetary Independence in Spite of Fixed Exchange Rates" NBER WP \#4207.

Svensson, Lars E.O. (1993) "Assessing Target Zone Credibility" European Economic Review 37, 763-802. 


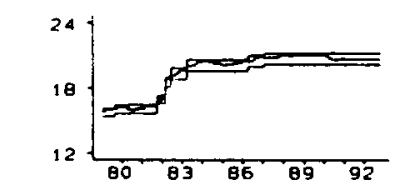

Belgium-Luxembourg
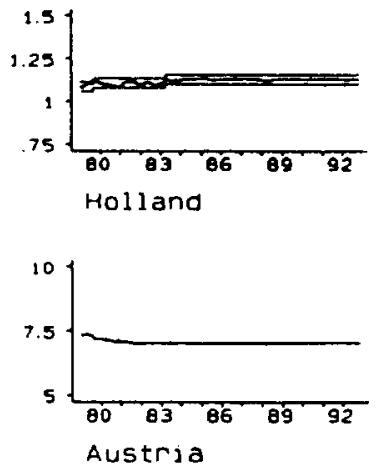

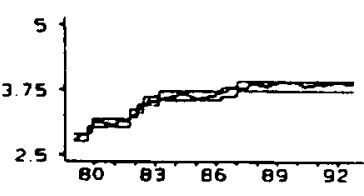

Denmark
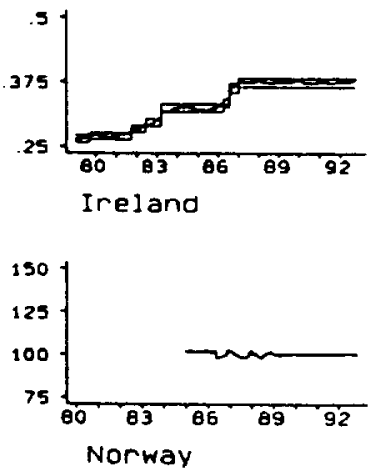

Price of a $O M$
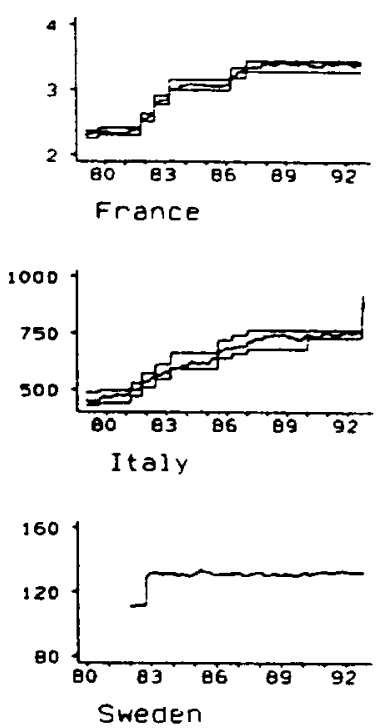

Time Series of Exchange Rates

Figure 1: Raw Exchange Rates
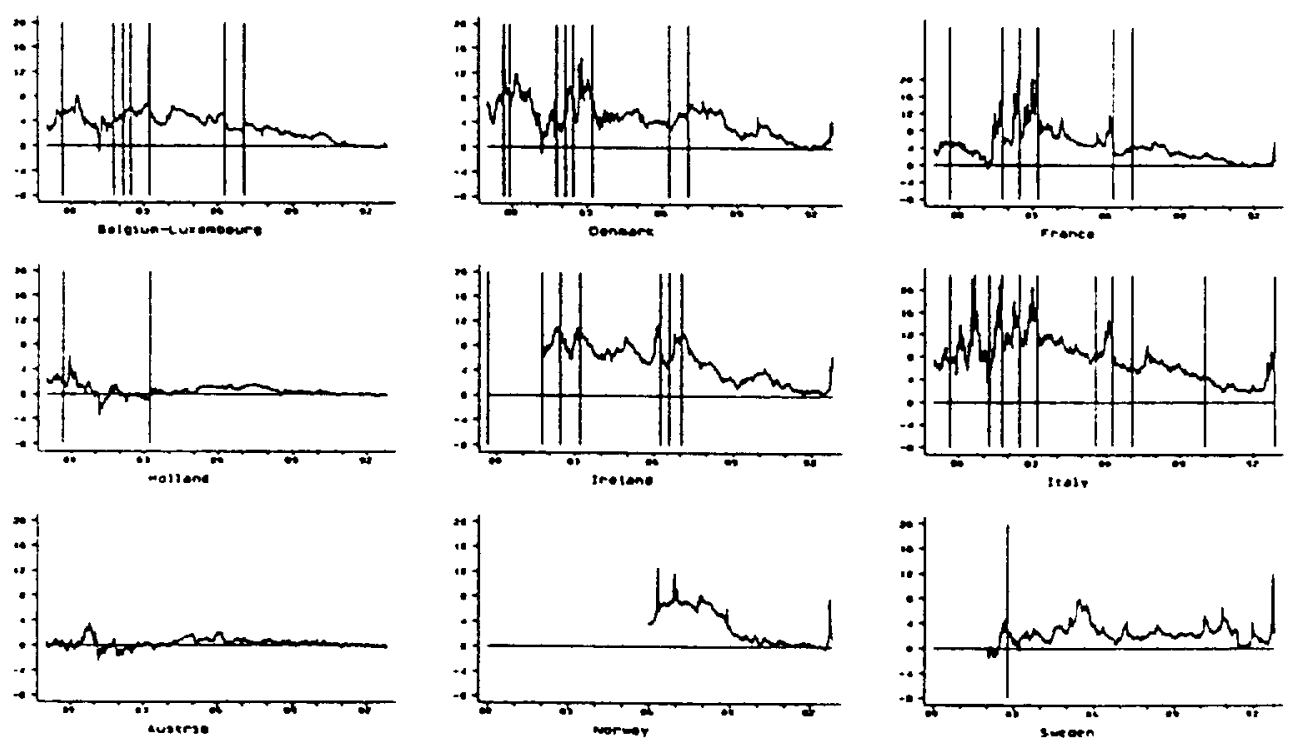

Three-Month Maturity; Domestic minus German Rate

Time Series of Interest Rate Differentials

Figure 2: Raw Interest Differentials 


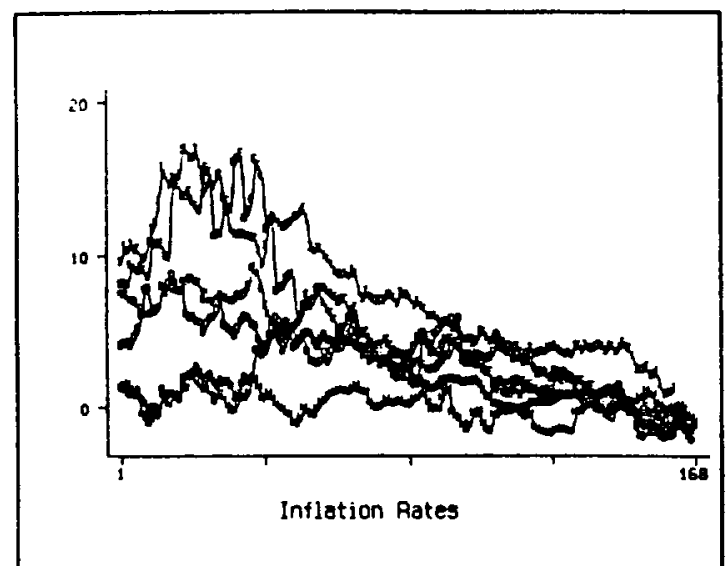

Figure 3: Inflation Time Series

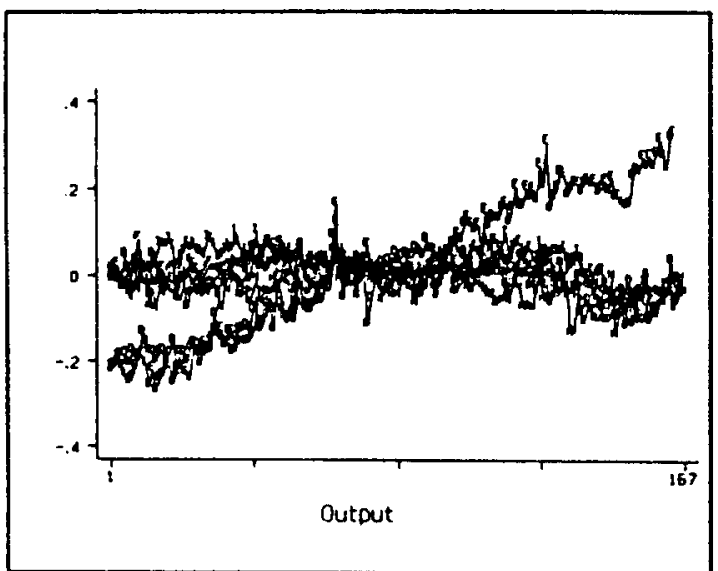

Figure 5: Output Time Series

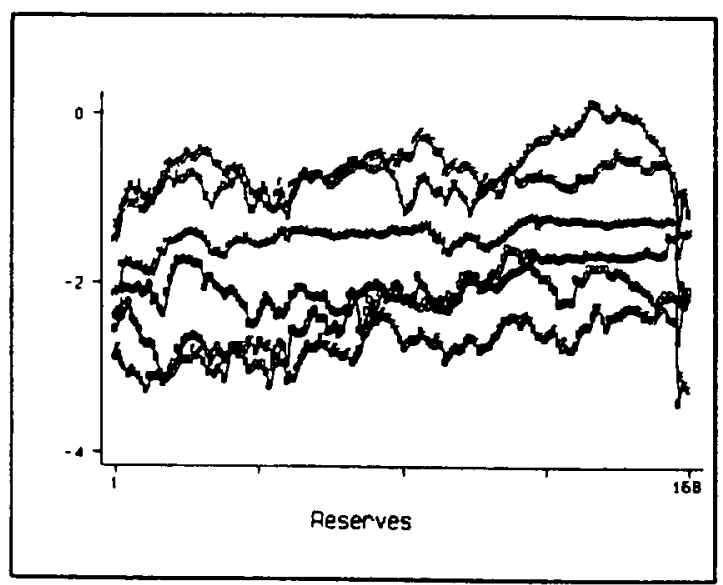

Figure 7: Reserves Time Series

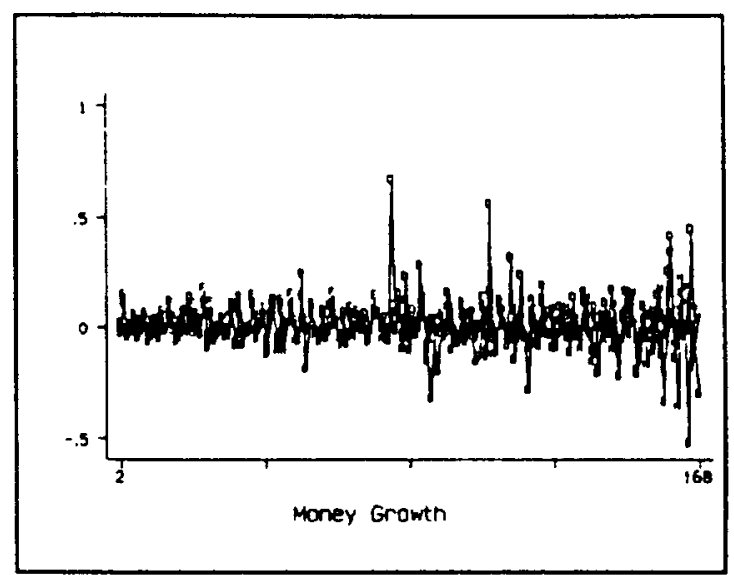

Figure 4: Money Growth Time Series

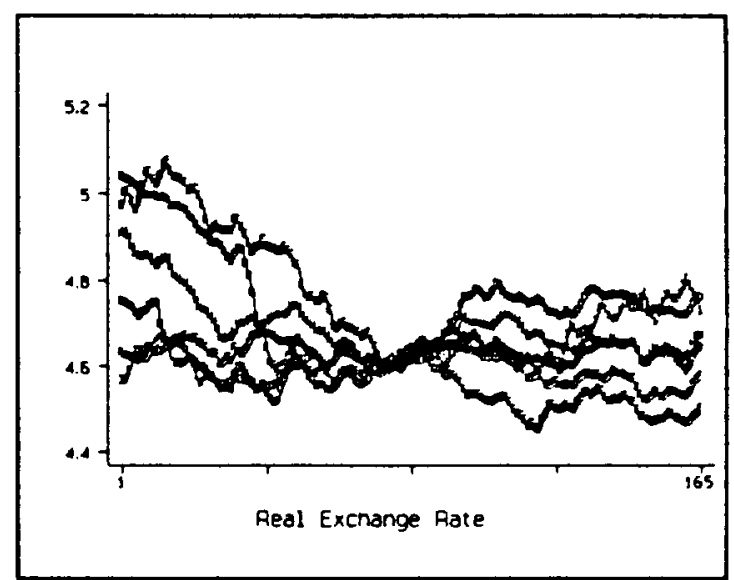

Figure 6: Real Exchange Rate Time Series

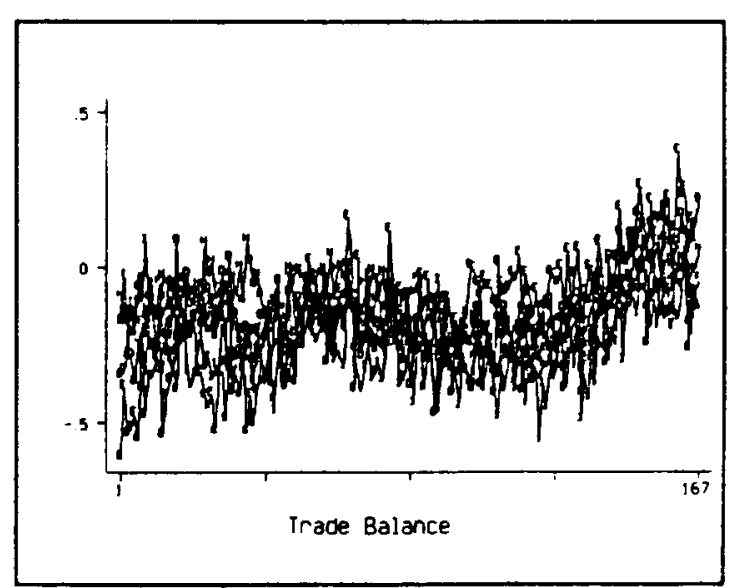

Figure 8: Trade Balance Time Series 


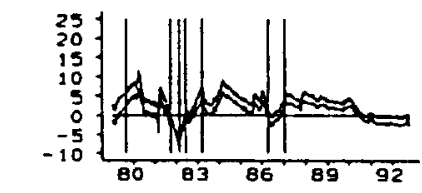

Belgium-Luxembourg
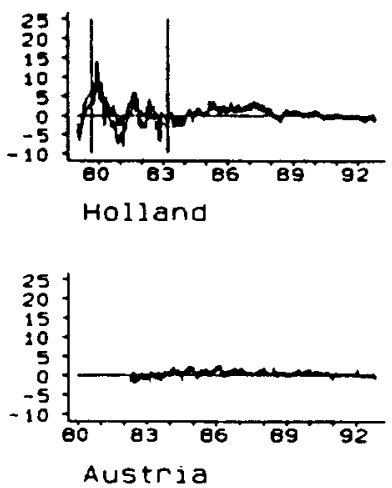
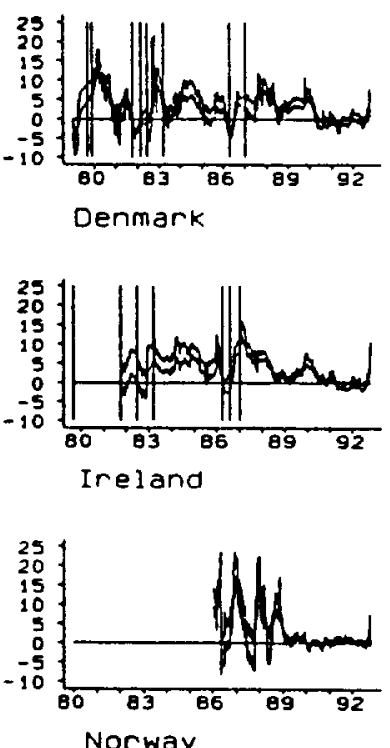
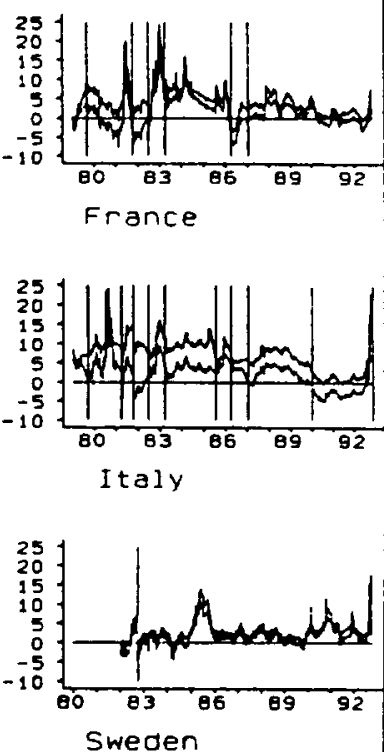

Sweden

95\% Confidence Intervals, Three-Month Measures

Time Series of Expected Realignment Rates

Figure 9: Estimated Realignment Expectations Measures

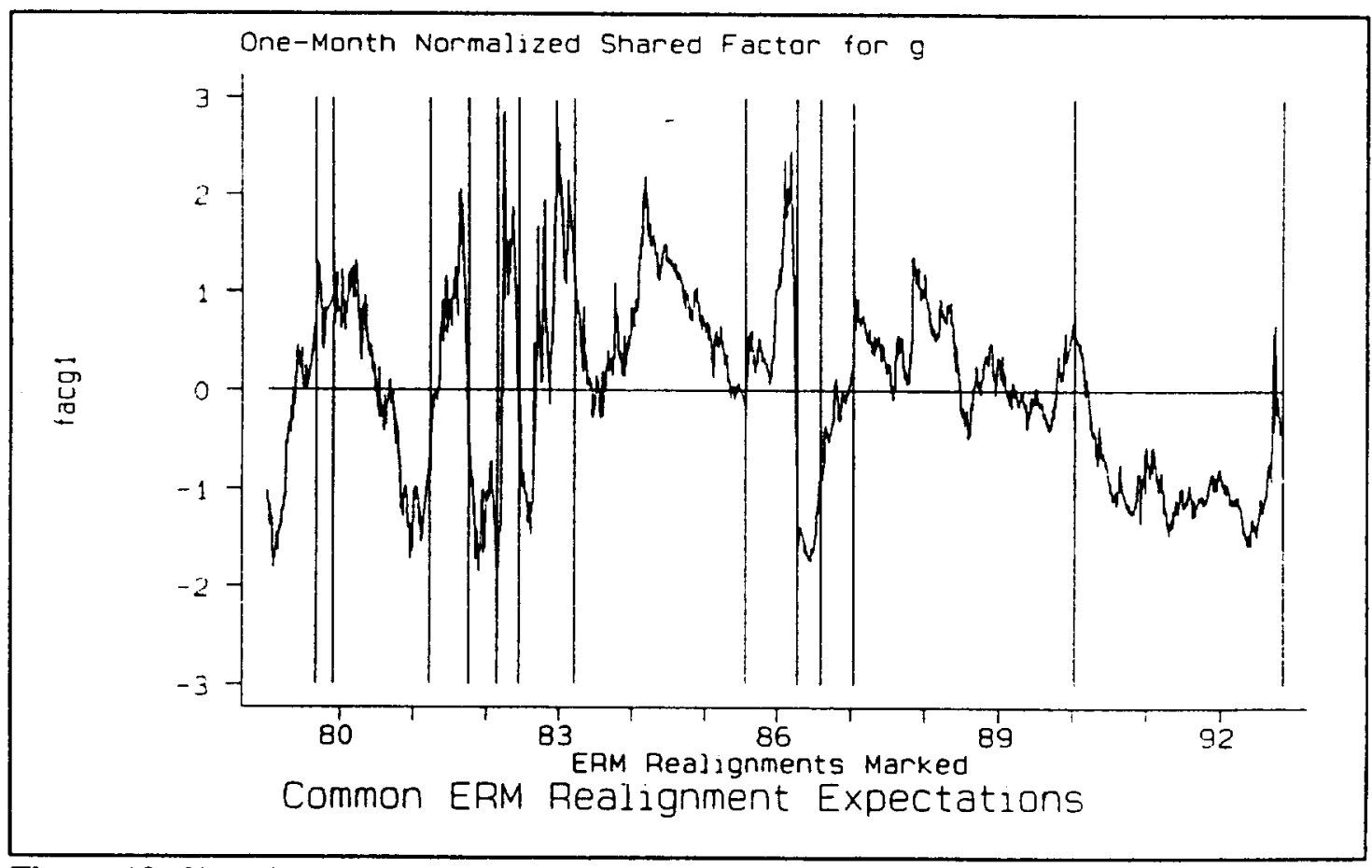

Figure 10: Shared ERM Realignment Expectations Measure 
Long-Term ERM Participants; Three-Month Measure of $g$
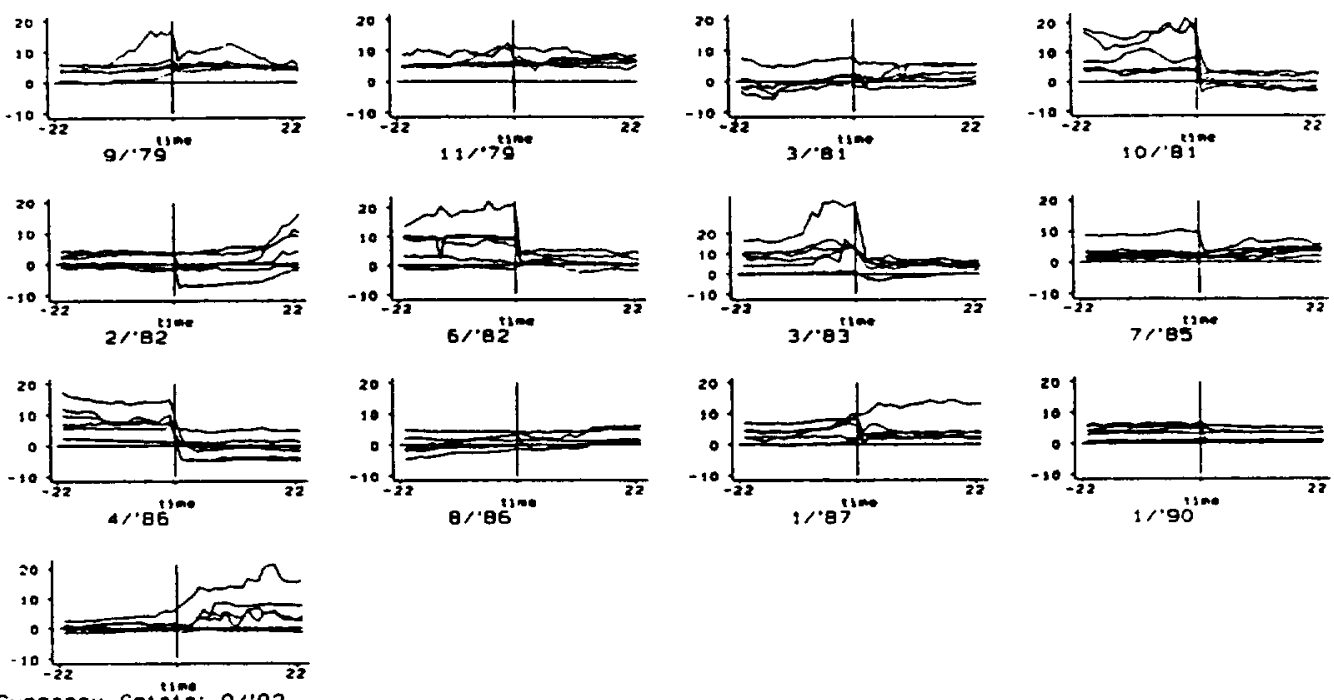

One Month before and after Actual ERM Realignments

Realignment Expectations around Realignments

\section{Figure 11: Realignment Expectations around Realignments}

January 1991 through October 1992
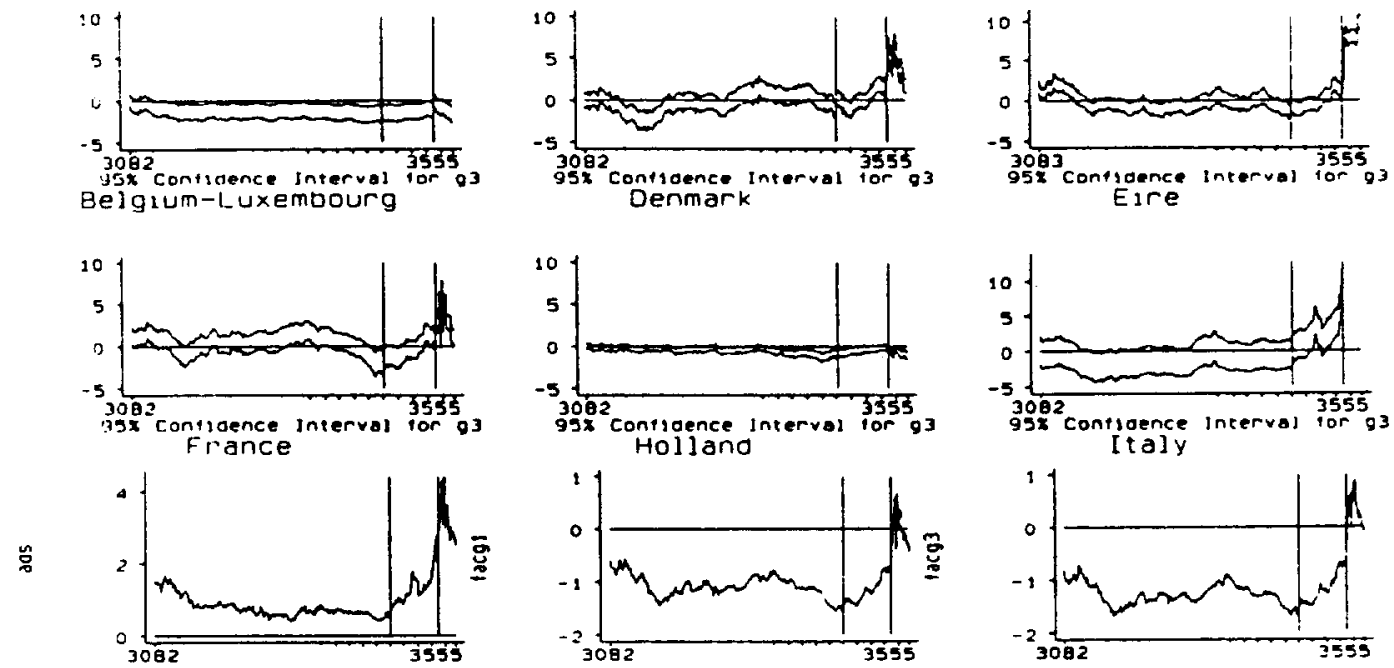

Average One-Month oelta
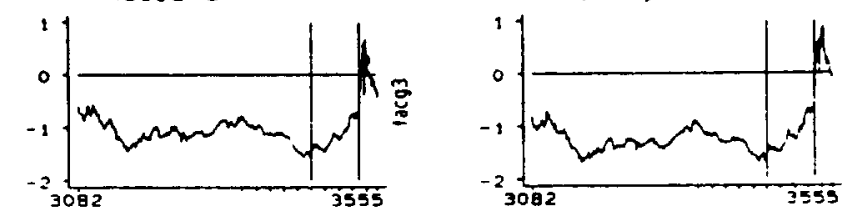

One-Manth $g$ Factor

Three-Month o Factor

1992 Months Ticked; Danish Reterendum and Black Wednesday Marked

Realignment Expectations Before and Through the Crisis

Figure 12: ERM Realignment Expectations and the Currency Crisis 
Domestic minus German rate

Danish Referendum and Black Wednesday marked

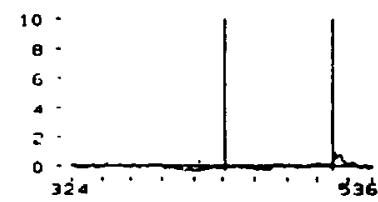

Belgium-Luxembourg

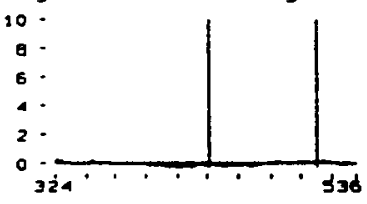

Holland
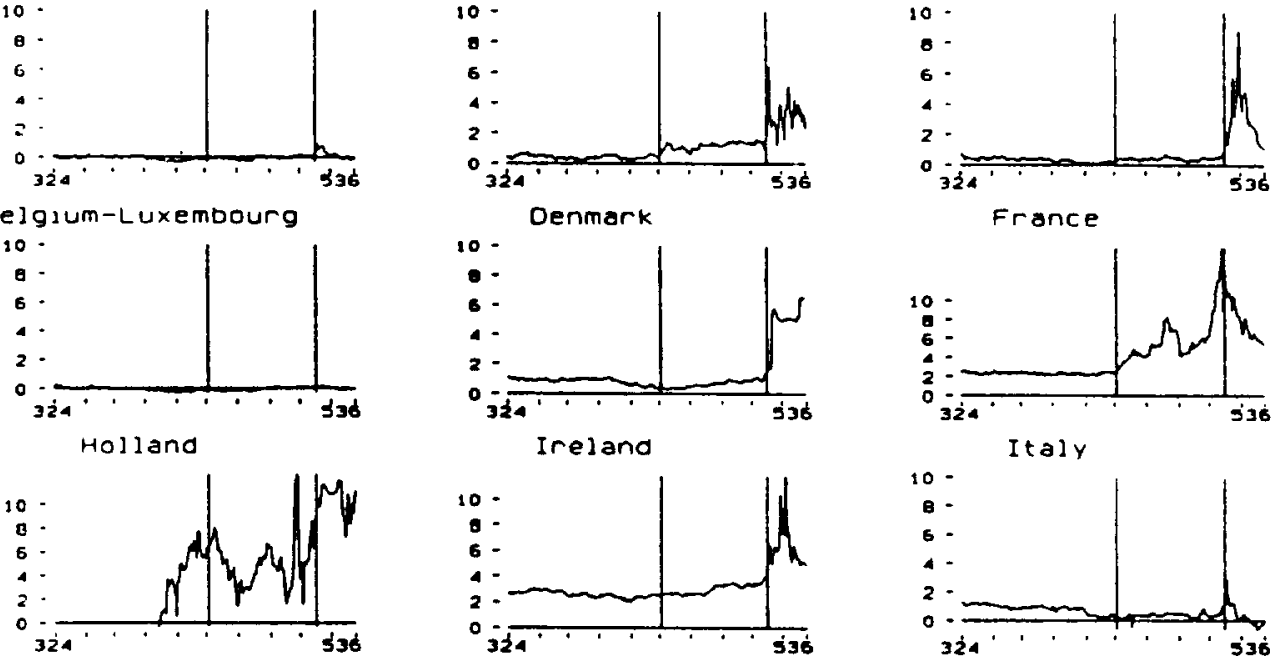

Portugal

1/1/1992 through 10/26/1992, months ticked

One-Month Interest Rate Differentials in 1992

Figure 13: Short Interest Differentials in 1992 


\section{Endnotes}

1. We rely on uncovered interest parity holding at least approximately, despite the evidence against this hypothesis in floating exchange rate regimes (e.g., Froot and Thaler (1990)). The UIP hypothesis works well for France during the ERM period, but worse for the other countries, typically being rejected at reasonable significance levels. A discussion of the relevant deviations from uncovered interest parity can be found in Rose and Svensson (1993). A small time-varying exchange risk premium which might account for the deviations from UIP will not significantly affect our results unless its movements coincide with changing realignment expectations for some mysterious reason.

2. If $x$ jumps at realignments, then the devaluation of the spot exchange rate which occurs at realignments will not coincide with the size of the central parity realignment; see Rose and Svensson (1993) and Svensson (1993) for further discussion.

3. This estimation procedure does not guarantee that expected future exchange rates within the band are constrained to lie within the band limits. Chen and Giovannini (1992) have suggested that this issue be handled by a logistic transformation of the exchange rate within the band, using the explicit bandwidth. However, the underlying (target-zone) exchange rate theory does not suggest such a transformation, which may also work badly in practice since it prevents predicted future exchange rates from actually reaching the edges of the band. In addition, the procedure relies on explicit maximal bandwidths, which may be irrelevant in practice either because of implicit bands, or more narrow effective limits which result from the multilateral nature of the ERM. Lindberg, Svensson and Söderlind (1991) and Rose and Svensson (1993) have compared this technique to the method used above, and found very similar results. In any case, reasonable confidence intervals of expected future exchange rates within the band for our estimates almost never lie outside the band.

4. Our STATA data sets and programs are available on receipt of two formatted highdensity $3.5^{\prime \prime}$ diskettes with a self-addressed stamped envelope.

5. The questionable data points are: 1-3-1983 (Italian 1-month rate); 1-30-1984 (German 1-month rate); 8-1-1985 (French 1- and 3-month rates); 9-14-1992 (Italian 1-month rate); 9-18-1992 (Danish 1-month rate); and 10-1-1992 (Danish 3-month rate).

6. The ERM is a multilateral peg, so that effective bilateral limits are sometimes much more narrow than notional bilateral limits. Thus the pound might be much more constrained in its movements vis-a-vis the DM if the peseta is close to its ERM limit, since the pound is constrained vis-a-vis the peseta.

7. The gentle improvement in credibility that characterizes the post-1987 era also characterizes the three shorter-term ERM participants, Portugal, Spain, and the UK.

8. While the hypothesis of a unit-root cannot typically be rejected at standard significance levels for the six macroeconomic variables we consider (in log-differential form), this is not true of either the mean of $g$ or the degree of exploited monetary independence. Thus conventional co-integration techniques cannot be used to investigate the relationships between macroeconomic variables and credibility. Still, any steady-state relationship between $g$ and the regressors should be easy to detect with this quasi-co-integrating regression. 
9. If the covariance matrix were estimated with an instrumental variables technique to take account of any generated regressor effects, our negative results would almost surely be strengthened.

10. This finding is consistent with the less formal work of Eichengreen and Wyplosz (1993) who show that Italy was the only clear case of an EMS country which suffered a decline in competitiveness before the currency crisis.

11. This indicates that our use of a panel data set may reconcile our results with the more positive findings of Caramazza (1993), who analyzes an analogue to (4) with French timeseries data.

12. As mentioned in footnote 9, the macrocconomic variables appear to have unit-roots; in fact, they also typically appear to be close to individual random walk processes. Thus, first-differencing the data roughly transforms the data from levels to innovations. The negative results of the first-differenced VAR can thus be interpreted as an absence of strong links between credibility and macroeconomic news.

13. As suggested by Chen and Giovannini (1993), we also included (lags of the time from the latest realignment in our regressions. The null hypothesis that the cumulative impact of (lags of) time from the latest realignment is zero cannot be rejected in our panel regressions at even the .1 significance level.

14. Parenthetically, the volatility of expected exchange rate drift also appears to have few statistically significant cumulative effects on the six macroeconomic variables.

15. Contemporaneous correlations are also high between the ERM countries, Austria and Norway (but not Sweden).

16. The factor was estimated using the one-month measure of $g$ on the data for all sixlong-term ERM members since 1981 (and the comparable data on these countries less Eire for the period when the Irish data are unavailable). The actual (post-1981) equation used to generate the factor uses the scoring coefficients for $g_{1}$, so that it equals $\mathrm{f}_{1}^{1}=.21 \mathrm{gD}^{1}+$ $.18 \mathrm{~g}_{\mathrm{a}}^{1}+.41 \mathrm{~g}_{\mathrm{A}}^{1}+.05 \mathrm{~g}_{\mathrm{H}}^{1}+.20 \mathrm{~g}_{\mathrm{l}}^{1}+.15 \mathrm{~g}_{\mathrm{B}}^{1}$, where the $\mathrm{g}$ measures are all for the onemonth market and the subscripts denote: Denmark; Belgium-luxembourg; France; Holland; Italy; and Eire.

17. The extracted factor measuring shared ERM realignment expectations does not appear to be very well explained by purely German macroeconomic variables. While there are signs of a significantly negative effect of German inflation on shared realignment expectations, most macroeconomic variables have insignificant effects and most movements in the factor cannot be well explained by German macro-phenomena.

On a related note, the Section $V$ finding of few significant relationships between macroeconomic variables and realignment expectations holds up if equation (5) is estimated using only the country-specific component of realignment expectations as the regressand, so that there are few statistical ties between macroeconomic variables and idiosyncratic credibility.

18. Eichengreen and Wyplosz (1993) argue that the currency crisis stemmed in part from doubts about the likelihood of EMU, as do the Commission of the European Communities (1993) and the Group of Ten (1993). However, Froot and Rogoff (1991, p 270) contend 
that faster transition to EMU is more likely to destabilize the EMS, stating "... intra-EMS interest-rate differentials might begin rising sharply as union draws closer."

19. On page 64 of the April 4 issue, The Economist stated that "The biggest threat to [Maastricht] ratification comes from Denmark. Opinion polls suggest that a slight majority will vote no in the June referendum." Much closer to the actual date, on page 58 of the May 23 issue, the same magazine stated that "... ordinary Danes will have their own chance to vote on the treaty in a referendum on June 2 nd. Opinions polls show them equally divided for and against ..."

20. On August 24, the Economist Intelligence Unit (EIU) wrote in its Italy Country Report 3 (1992, p 7) [bold type not added]:

"Exchange rate stability will be maintained -

The lira is currently overvalued against the Deutschemark on purchasing parities and there have been constant rumours of a lira devaluation. Pressure on the lira, which was trading close to its floor with the Deutschemark in July, was relieved, as investor confidence was restored. The Bank of Italy is committed to exchange rate stability as the cornerstone of its general economic policy ... the government remains committed to maintaining its central rate within the ERM and will allow interest rates to rise if it shows signs of further decline. - and a devaluation is extremely unlikely

In this context, a devaluation would be resisted by the central bank, as well as by the government ... A positive result in the French Maastricht referendum would give a new fillip to monetary integration and diminish fears that Italy will renege on its convergence commitments. However, if the European project is derailed by popular opposition, then a new run on the lira can be expected, reviving the devaluation option, but only, in that event, within an EMS realignment."

Parenthetically, in its France Country Repor 3 (1992, p7), issued on July 17, the EIU stated "The EIU foresees no marked weakening of the franc against the Deutschemark in 1992 and 1993, provided German monetary policy is tightened no further." In its Germany Country Report $3(1992$, p12) issued August 4, the same institution claimed that [through the fact that the Lombard rate was unchanged on July 16] "... the Bundesbank has offered the prospect of stability in money market rates and within the Exchange Rate Mechanism, at least in the short term ..."

21. Even a week before, there was little comment in the public press about European currencies; the Foreign Exchange section of the Wall Street Journal on August 18 stated that "... a lack of news kept most major currency players sidelined ..." In its Chronology of Events Preceding and Following the September 1992 Crisis in the European Monetary System, the Group of Ten (1993) lists eight events from June 21993 (the beginning of the chronology) to August 27 , compared with over seventy afterwards.

22. Although its "Economic Focus" column tackled the subject of exchange market efficiency. Even more ironically, on May 16 the same newspaper wrote an article asking "... could sterling aspire to replace the D-mark as the ERM's anchor currency?"

(Economist, p. 29). 